\title{
La Lima del viandante ¿Qué nos dice la ciudad a los que osamos ser caminantes?
}

\author{
Javier Díaz-Albertini F. \\ (Universidad de Lima, Perú)
}

Recibido: $10 / 4 / 2015$

Aprobado: 1/6/2015

\begin{abstract}
Resumen. En los últimos años, Lima ha sufrido un acelerado proceso de privatización de sus espacios públicos, en el cual el caminante ha ido perdiendo acceso a la ciudad. Para analizar esta tendencia se escogieron tres aspectos que manifiestan este carácter discriminatorio: las veredas como vías propias del caminante; los cruces peatonales como lugar de encuentro con los motoristas; y el acceso a servicios higiénicos públicos. En cada aspecto presentamos imágenes de cómo el caminante debe hacer frente a una ciudad agresiva, hostil y peligrosa, que no solo le niega un adecuado acceso y uso al espacio público, sino que también rebaja su estatus ciudadano al vulnerar sus derechos, especialmente al libre tránsito.
\end{abstract}

Palabras clave: peatones / veredas / espacio público / privatización / libertad de tránsito

\section{Lima of the Rambler. \\ What does the City Say to Those that Dare to be Pedestrians?}

SumMARY. In the last few years, Lima has undergone an accelerated privatization process of its public space. In this process, pedestrians have gradually lost access to the city. In order to analyze this tendency, three central aspects in which pedestrian discrimination can be observed were selected: sidewalks as pedestrians' thoroughfare; pedestrian crossings as places of interrelation with motorists; and the access to public restrooms. Images are presented regarding each of these aspects of how pedestrians must face an aggressive, hostile and dangerous city that not only denies adequate access and use of public space, but also demeans his/her citizen status by undermining his/her rights, especially those of free passage.

Key words: pedestrians / sidewalks / public space / privatization / free passage 


\section{Introducción}

$\mathrm{H}$ ace unos años comencé un estudio sobre las nociones y el uso del espacio público en Lima, especialmente en los distritos con fuerte presencia de los niveles socioeconómicos medios-altos (NSE A/B). Parte de la metodología del estudio comprendió recorrer la ciudad a pie, caminando por sus plazas, parques, barrios y calles, en lo que solemos llamar observaciones "en sitio". No es que fuera una novedad que me paseara por la ciudad, ya que llevo más de treinta años trotando por las calzadas, bermas y veredas de Lima. Pero ahora lo hacía con el ojo inquisidor de sociólogo andante y sensibilizado por lo que iba descubriendo gracias a las encuestas, visitas, los grupos focales y las entrevistas que se iban realizando en el marco de la investigación ${ }^{1}$.

En Lima encontramos dos tendencias contrapuestas:

- Una primera - poderosa y hegemónica- se caracteriza por privatizar la ciudad, incluyendo sus espacios públicos (Vega Centeno, 2006; Ledgard y Solano, 2011; Ludeña 2011,
Gonzales de Olarte et al., 2011). Aunque no hay acuerdos inequívocos sobre lo que implica la privatización, es posible definirla como un conjunto de procesos y acciones que privilegia la iniciativa privada como principal determinante de las políticas y decisiones urbanas. El desarrollo de la ciudad resulta, entonces, del agregado de iniciativas particulares, normalmente teniendo al mercado como principal mecanismo para la toma de decisiones. Otras esferas de toma de decisiones -como las gubernamentales, comunales o familiares- pasan a un segundo lugar o son consideradas subyacentes a los intereses particulares. Según Logan y Molotch (2007), en el nuevo urbanismo se favorece el valor de cambio sobre el valor de uso, a pesar de que este último resulta esencial para entender las disposiciones de la mayoría de los habitantes de una urbe, especialmente en la creación de lugares. Este impulso privatizador afecta al espacio público: rejas en calles y urbanizaciones, parques cerrados o que cobran entrada, veredas tomadas por residentes y comerciantes,

1 La investigación, apoyada por el Instituto de Investigación Científica de la Universidad de Lima, se titula "Espacio público, identidad territorial y ciudadanía en Lima" y siguió una metodología en gradación -de general a específico- que permitió múltiples miradas, enriqueciendo así la información para el análisis: (a) Encuesta representativa; (b) Observaciones y visitas semiestructuradas; (c) Grupos focales con mujeres NSE A, jóvenes NSE A/B, skaters y deportistas; y (d) Entrevistas a funcionarios municipales encargados del espacio público en ocho distritos y de Servicio de Parques (Serpar-Lima). 
calles dominadas por un transporte público descontrolado, áreas verdes destruidas por alcaldes, playas que excluyen de facto a ciertos usuarios, y muchos casos más. Los procesos de privatización se ven respaldados por la hegemonía de la propuesta liberal que cuestiona y rebaja la acción pública (Xu y Yang, 2008) y por los miedos urbanos que van en aumento ante el incremento de la delincuencia real y percibida. En Lima, sin embargo, la informalidad le otorga un carácter especial (y perverso) a la privatización. Es decir, muchas de las acciones que privatizan se realizan al margen de la normativa vigente y constituyen una apropiación de facto de los espacios que nos pertenecen a todos ${ }^{2}$.

- Una segunda tendencia -aún tímida, pero valiente- es el creciente vuelco hacia el espacio público, producto de una serie interrelacionada de hechos: (a) la mayor verticalidad y densificación de las áreas residenciales y el menor metraje cuadrado de la vivienda lleva a una mayor publicidad de las actividades urbanas; (b) un aumento en la preocupación por la salud, que tiene como respuesta un mayor número de caminantes, corredores, ciclistas y deportistas; (c) la creciente conciencia ambiental lleva necesariamente a una demanda por más áreas verdes públicas y a un uso más intensivo de las veredas (peatón, skater, patinador, ciclista); (d) un incremento en la actuación municipal sobre los espacios públicos en el intento de aumentar visitantes y la actividad comercial, vía la peatonalización y la musealización de la ciudad, entre otros.

En el presente artículo veremos cómo se manifiesta la primera de estas tendencias en los espacios propios del caminante urbano. Y lo haremos analizando algunas imágenes de la Lima actual y cómo a través de ellas nos habla nuestra ciudad. Para ello, hemos escogido tres aspectos en los cuales se manifiesta claramente el carácter de contestación propio de todo espacio público ${ }^{3}$. Primero, veremos la situación

2 Basta mencionar un caso que veremos más adelante. Según la Asociación Peruana de Consumidores y Usuarios (Aspec), en 2010, el 93 \% de las rejas colocadas en las calles y urbanizaciones en Lima, que restringen el derecho al libre tránsito, no tenía autorización, a pesar de que ya existía -desde 2004- un reglamento para su implementación.

3 Aunque podríamos definir el espacio público de acuerdo a sus tres principales atributos, a saber: el acceso universal, la transparencia y la multifuncionalidad (Díaz-Albertini, 2012), es evidente que justo estas características son las que generan conflictos, pero también el diálogo y la negociación ciudadana. Por ejemplo, ¿qué se debe permitir en un parque en particular? ¿Se puede jugar fútbol? ¿Los perros cuentan con un sitio para sus necesidades? ¿Hasta qué hora puede haber bulla? ¿Cómo y quién cuida los jardines? 
de nuestras veredas, que son las vías propias del caminante urbano: hasta qué punto existe un proceso de privatización y cómo ello afecta al poblador de la ciudad. Segundo, analizaremos algunos cruces peatonales y la conducta de los caminantes ante ellos. Finalmente, veremos un caso particular de cómo algunos habitantes se están adaptando a una ciudad que comienza a generar un sentimiento de civismo, pero que aún no brinda el conjunto de oportunidades propicias para que se practique a plenitud. Sin embargo, antes de embarcarnos a apreciar el lenguaje no oral de Lima, nos interesa analizar brevemente la condición del caminante en las grandes urbes.

\section{El caminante urbano}

Javier Protzel, en su libro Espacio-tiempo y movilidad. Narrativas del viaje y la lejanía (2013), nos ofrece un informado y entretenido recuento de cómo la movilidad va cambiando nuestra visibilidad. Es decir, la velocidad del observador -que aumenta en forma creciente gracias a los avances tecnológicos de la Revolución Industrial- tiene un impacto directo sobre qué ve y cómo lo ve. El mencionado autor resalta este hecho al comparar a los viajeros del pasado -a pie o a caballo- y sus paisajes casi incambiables por horas o días y el esfuerzo físico que representaba el traslado, con los viajeros actuales que solo perciben un paisaje borroso con relativa comodidad, y como resultado "el cuerpo del viajero fue disociándose de su transcurso" (2013, p. 28, las cursivas son del original).

Algo parecido ocurre a menor escala en nuestros traslados en una urbe. La velocidad de desplazamiento del observador tiene un efecto determinante en la forma que asume el paisaje urbano. Un caminante se desplaza a un máximo de cinco kilómetros por hora, mientras que un motorista (si el tráfico lo permite) puede avanzar a velocidades que oscilan entre los treinta a ochenta kilómetros por hora. El caminante, además, se encuentra casi siempre en contacto directo con el suelo y el medio (aire, clima, temperatura), no tiene que preocuparse de la conducción de una máquina de más de una tonelada de peso y normalmente solo debe atender el flujo del tráfico al intentar cruzar la calle. Por el contrario, el motorista se encuentra elevado del suelo, encapsulado en una máquina, distanciado del medio y -esperemosatento al flujo del tráfico.

Es evidente, entonces, que lo que percibe un caminante es muy distinto a lo que percibe el que conduce o se encuentra en un vehículo. Al motorizarse nuestras ciudades, el poblador urbano fue perdiendo la noción del trayecto - de los matices y minucias del recorrido- y se fue convirtiendo en un ser meramente consciente del punto de partida y del arribo. Como señala Protzel, el cuerpo fue disociándose de su transcurso. El poblador de una ciudad concentrada y densa -como es el caso de urbes como Nueva York- tiene que caminar y es más consciente de la ciu- 
dad en lo que podríamos llamar una escala micro. Por eso son ciudades de cafés, bares, parques, bodegas, restaurantes y librerías de barrio - pero que a su vez atienden a la metrópoli- porque el caminante detecta estos establecimientos y van adquiriendo el estatus de "lugares" (y no "sitios") ${ }^{4}$. El habitante limeño promedio, por el contrario, se ha motorizado porque vive en una ciudad aún plana y sobreextendida. Al subir al carro, transporte público o motocicleta ya tiene como finalidad un destino claramente definido, visible en su mapa mental y de escala macro (el centro comercial, el centro financiero, las franquicias de café, hamburguesas, pizzas o pollos). No tiene tiempo, paciencia o ganas de examinar lo que ofrece la ciudad en el camino ${ }^{5}$.

El transporte motorizado transformó a buena parte de las ciudades del mundo. En primer lugar, facilitó el éxodo de los sectores altos y medios del centro de la ciudad hacia nuevas urbanizaciones, en búsqueda de la promesa bucólica del suburbio y de mayor privacidad (Francis, 1991). En segundo lugar, hizo posible que la distancia entre el trabajo y la residencia aumentara, ya que permitía un traslado más rápido a distancias mayores. En tercer lugar, aumentó la peligrosidad, ya que la principal causa de muerte y accidentes en toda metrópoli tiene como responsables a los choferes. En cuarto lugar, el aumento del parque automotor también modificó el diseño y la configuración física de la ciudad, principalmente generando una infraestructura que prioriza el flujo y la velocidad de desplazamiento. En quinto lugar, ha modificado el comportamiento del habitante de la ciudad, principalmente en términos de la actividad física realizada en sus desplazamientos:

De esta manera, el desarrollo de las ciudades se encuentra en estrecha relación con la incorporación masiva de medios de transporte en la vida cotidiana. La urbe fue reorganizada para privilegiar la circulación. Para ello se construyeron amplias vías, entre las que la autopista fue la más importante, que facilitaron los desplazamientos acelerados... la urbanización implica la integración de la movilidad como elemento estructurante de la vida cotidiana (Bielich, 2009, p. 10).

4 El concepto de "lugar" es utilizado en las ciencias sociales para definir un espacio que ha sido dotado de significados personales o sociales y normalmente se expresa en el grado de "apego al lugar" -o place attachment en inglés (Smalldone et al., 2008).

5 La ciudad de escala micro es una urbe de "huariques", término peruano que significa "escondrijo, lugar secreto". En los últimos años, su significado ha tendido a emplearse para designar aquellos sitios que preparan deliciosos platos y potajes pero que no son conocidos por el común de las personas (especialmente aquellos de mayores ingresos). Parte del "boom gastronómico" del país ha sido rescatar y difundir estos huariques $\mathrm{y}$, al hacerlo, que dejen de serlo. 
Pero quizás el efecto más importante es el que ha tenido sobre el espacio público. Uno de los principales estudiosos al respecto fue Donald Appleyard (1981), que a principios de los años sesenta realizó un estudio clásico en la ciudad de San Francisco, comparando tres vecindarios: el primero con un flujo de tráfico de 2000 vehículos al día, otro de 8000 y el tercero con 16000. Su estudio mostró cómo los residentes de la calle menos transitada tenían tres veces más amigos y dos veces más conocidos que los residentes de la más transitada. Appleyard, y luego su hijo (Bruce Appleyard, 2005), tienen como punto de partida insistir en la importancia de la calle como espacio público, el más común o asequible de todos. La calle es compartida por el peatón, el ciclista, el automovilista y el tráfico destinado a los diversos servicios de la ciudad. Con el tiempo, sin embargo, se ha perdido el equilibrio en los usos compartidos $\mathrm{y}$ ha terminado siendo dominado por el automóvil. A mayor flujo de tráfico menor es el ámbito y la frecuencia de interacción en una calle o barrio. La razón principal es que el flujo restringe el desplazamiento del residente-peatón, especialmente dificultando que cruce la calle, pero también a que la considere como un lugar hospitalario. Asimismo, restringe la actividad recreativa de los niños y niñas que usualmente es una de las razones detrás de la presencia adulta en la calle (supervisándolos) y elemento de interrelación entre padres de familia y vecinos.
Otros estudios muestran que no solo resulta importante el flujo del tráfico, sino también la velocidad. Pucher y Dijkstra (2003), por ejemplo, examinaron por qué los norteamericanos se trasladaban menos a pie o en bicicleta que los alemanes y holandeses. Una de las razones principales era el peligro que representaba el tránsito automotor: en Estados Unidos, por cada kilómetro transitado, es veintitrés veces más probable que un peatón (doce veces un ciclista) se accidente mortalmente que un automovilista. Un peatón estadounidense tenía entre tres veces (comparado con Alemania) y seis veces (con Holanda) más probabilidad de ser atropellado que los peatones de estos países europeos.

La razón principal detrás de estas diferencias es que los gobiernos y la sociedad civil de los países europeos llevan un cuarto de siglo actuando con el fin de que el espacio público sea más amigable y seguro para los que se trasladan a pie o en bicicleta. Esto incluye acciones destinadas a: 1) más y mejor infraestructura al servicio de los peatones y ciclistas; 2) disminución de la velocidad de los vehículos -en inglés traffic calming o "pacificación del tráfico" en castellano (por ejemplo, estudios en Inglaterra muestran que el riesgo de muerte de un peatón en casos de atropello aumenta de $5 \%$ cuando la velocidad del vehículo es de $20 \mathrm{kph}$ a $80 \%$ cuando es de $40 \mathrm{kph}$ ); 3) diseños urbanos orientados al acceso del peatón y ciclista a los espacios públicos y la restricción del uso del automóvil (in- 
cluye, en el caso de Holanda, el llamado woonerf, calles en las cuales el peatón y el ciclista tienen prioridad, o las calles peatonales, véase Francis, 1991); 4) educación vial acompañada de un sistema eficiente de reglamentos y sanciones ${ }^{6}$.

En la ciudad de Lima, según el especialista Juan Carlos Dextre, vivimos una esquizofrenia total porque no llegamos a optar por un modelo de ciudad y, por ende, de su flujo e infraestructura vial ${ }^{7}$. A veces, escogemos el modelo de las ciudades norteamericanas que surgen con el uso del auto privado (por ejemplo, Los Ángeles) y por eso exigimos una mayor inversión en infraestructura para estos vehículos (autopistas). En otros momentos, no obstante, apostamos por el transporte público, la caminata y la bicicleta, por la gestión inteligente y cuidadosa de la infraestructura existente. Bajo estas circunstancias lo que hacemos es alentar formas contradictorias de transporte, que se traducen en más congestión, contaminación y pérdidas económicas.

¿Cuánto caminamos los limeños y las limeñas? ¿Con qué finalidad lo ha- cemos? ¿Qué riesgo acarrea? ¿Cuánto usamos nuestras pistas y veredas?

- Un estudio sobre la vulnerabilidad del peatón, elaborado por el Ministerio de Transportes y Comunicaciones (MTC), señala que $25 \%$ de todos los traslados realizados en Lima-Callao en un día son caminatas (MTC, 2009). Es un porcentaje mucho más alto que el registrado en Bogotá, Colombia $(15,1 \%)$ o como promedio en Estados Unidos $(8,6 \%)$. Después del uso del transporte público (52\%), es la segunda forma más común de trasladarse en la ciudad. Como modalidad, es usada fundamentalmente para ir al colegio ( $35 \%$ de todas las caminatas) o para ir de compras (26\%). De ahí que el estudio concluya que una gran parte de las caminatas son realizadas por niños/niñas y jóvenes (escolares) y amas de casa (compras). Son relativamente pocas las personas que caminan a su trabajo.

- Según la última encuesta de "Lima cómo vamos" de 2014, no solo caminamos con la finalidad de

6 Debido al creciente interés por los espacios públicos es que en las grandes urbes se están generando movimientos cívicos en favor de la recuperación de la ciudad para sus habitantes, especialmente los que van a pie. En Nueva York, por ejemplo, existe la organización Project for Public Spaces" (PPS), cuyo lema es making places o "creando lugares", que justo busca hacer del espacio público un territorio con significado y valor para el individuo. Entre las principales medidas que impulsan está el control al tráfico vehicular (véase http://www.pps.org/).

7 http://puntoedu.pucp.edu.pe/entrevistas/transporte-en-lima-vivimos-en-una-esquizofrenia-total/ del 5 de marzo de 2015, consultado el 12 de marzo de 2015. 
trasladarnos, ya que "ir a parques a pasear" es la principal actividad recreativa de los limeños y limeñas (70,3\% de los encuestados), en un lejano segundo lugar se encuentra "ir a bailar" (40,5 \%). En la encuesta realizada en Lima metropolitana para nuestro estudio, el $40 \%$ manifestó que visitaba un parque o una plaza por lo menos una vez a la semana, siendo mucho más común en el nivel socioeconómico NSE A $(63,8 \%)$ que en el NSE E (19\%). Esta diferencia se debe al mayor acceso a los parques de los sectores de mayores ingresos.

- Ser peatón en Lima es peligroso: $78 \%$ de las muertes por accidentes de tránsito tiene como víctima a un peatón:

por cada 100 mil viajes realizados a pie mueren por accidentes de tránsito 8 personas, mientras que por cada 100 mil viajes en otros modos muere menos de una persona por accidente de tránsito.

En pocas palabras resulta 10 veces más riesgoso movilizarse caminando en la ciudad que ir al interior de un vehículo (como conductor o pasajero), situación que es penosamente resaltante y demuestra la vulnerabilidad del peatón frente al vehículo, por las diferentes avenidas y calles de la urbe, principalmente si uno de los principales modos de transporte es la caminata (MTC, 2009, p. 9).

- El temor a la imprudencia de los motoristas es uno de los factores que ahuyenta a los pobladores y parcialmente explica el creciente éxodo de las calles y veredas. En nuestra encuesta preguntamos: “En términos generales, ¿qué representa más peligro al salir a la calle en su vecindario: el ser víctima de un asalto o robo, o el ser víctima de una imprudencia de algún motorista (atropellos y choques)?". Es decir, comparamos lo que la mayoría de las encuestas descubre como el principal problema de Lima (inseguridad) con el tráfico. La respuesta nos sorprendió, ya que $32 \%$ seleccionó la imprudencia, oscilando entre $30 \%$ para el NSE B y $43 \%$ para el D. En la misma encuesta quisimos comparar la experiencia de "calle" de los adultos con respecto a los niños y las niñas de hoy. No debe sorprendernos que cerca de $80 \%$ de los limeños NSE A/B manifestó estar totalmente de acuerdo, o de acuerdo, con haber jugado frecuentemente en la calle de niño. Sin embargo, al preguntarles si los niños de sus vecindarios jugaban hoy en día en la calle, la respuesta positiva se redujo a $45 \%$. Este éxodo de la calle también está capturado en la encuesta "Lima cómo vamos", como se muestra en el cuadro 1:

- Según el informe "Lima cómo vamos", el aspecto que genera mayor insatisfacción -en relación con aspectos de movilidad y el transporte- es "el respeto y el cuidado de la seguridad del peatón", con el 60,2 \% que 


\section{Cuadro 1:}

Frecuencia que tienen los niños para salir a jugar en la calle, 2010 y 2014 (en \%)

\begin{tabular}{lrr}
\hline Frecuencia & $\mathbf{2 0 1 0}$ & $\mathbf{2 0 1 4}$ \\
\hline Siempre o casi siempre & 20,9 & 15,3 \\
Algunas veces & 29,8 & 28,6 \\
Nunca o casi nunca & 15,2 & 20,9 \\
NS/NR & 1,4 & 2,0 \\
\hline
\end{tabular}

Fuente: “Lima cómo vamos" (2014), p. 17.

Elaboración propia.

declara estar "insatisfecho", 32,1\% "ni satisfecho ni insatisfecho", y 7,3 \% "satisfecho". Sobre los peatones también declararon estar insatisfechos con "las veredas y los espacios para la circulación de los peatones" (47,2 \%) y "señalización de cruceros peatonales" (43,2\%).

Es evidente que la situación del tránsito en Lima es caótica, y esto se debe a una gran diversidad de factores, pero hay dos que particularmente tienen efecto sobre el espacio público. En primer lugar, la pobre organización y gestión del transporte público en la ciudad. La liberalización del transporte durante el primer gobierno fujimorista se realizó sin mayor criterio técnico y solo buscaba incentivar la inversión privada. Según Bielich (2009) en su estudio de las empresas de transporte en Lima y de sus políticas de contratación de chóferes, el sistema laboral lleva a que conduzcan en forma desesperada como forma de subsistencia. Lleva a una forma perversa de privatización de las calles y del servicio público, en el cual la competencia se utiliza como justificación para no respetar los parámetros establecidos del uso de la calzada.

Consideramos que uno de los factores clave que explica el modo de manejar de los choferes recae en el sistema laboral en el que se encuentran. No es que los choferes sean "unas bestias", como muchos limeños aseguran, sino que están inmersos en un sistema laboral que quizá los obliga a manejar así o, por lo menos, no desincentiva dicha práctica de manejo (Bielich, 2009, p. 1).

La invasión de carriles, la metida del auto, el pasarse la luz roja, el parar en medio de la pista para recoger-dejar pasajeros, son parte de las múltiples conductas transgresoras que tienen como finalidad sacar el mayor provecho posible de la situación y generar unos centavos. La competencia salvaje entre unidades (hay casi el doble de las necesarias) -cual "efecto dominó"- 
ha contagiado al resto de conductores de la ciudad que deben enfrentarse a una realidad anómica y competir con los demás vehículos -públicos o privados- para avanzar en el tráfico. En segundo lugar, las deficiencias en el control del tránsito, en hacer respetar las reglas y sancionar a los infractores, incentivan las actitudes temerarias. En medio de esto, el peatón y el ciclista salen perdiendo, por simple cuestión de masa y velocidad.

\section{Las veredas}

Comencemos con el espacio "natural" para el peatón o caminante urbano. Según estudiosos del tema, la vereda moderna surge en Europa solo después del gran incendio de Londres en 1666, cuando al reconstruir las calles se incluyó la vereda (o acera) para separar ciertos tipos de actividades del creciente tráfico a caballo y de carruajes (Loukaitou-Siderios y Ehrenfeucht, 2012). A diferencia de la ciudad medieval, que combinaba todos los usos en la misma vía, en la ciudad moderna se le va dando mayor seguridad al peatón, e inclusive en ciudades como París ello se convierte en parte de los planes modernizadores de la nobleza y burguesía ilustrada, y ya para mediados del siglo XVIII incluían trottoirs, promenades y boulevards como elementos distintivos de la creciente civilidad y publicidad de la ciudad. Durante el siglo XIX se fue ampliando la red de veredas en las ciudades europeas y norteamericanas, pero su carácter netamente "público" aún no estaba establecido, inclusive en muchas urbes se consideraba que era una extensión del frente adyacente a la propiedad privada y por ello muchos municipios obligaban a los propietarios a que construyeran las veredas correspondientes al frontis de su lote. Los propietarios, a su vez, podían hacer uso de este espacio. Muchos comercios, por ejemplo, las usaban para exhibir mercancías, colocar anuncios y hasta como depósitos.

Ya entrado el siglo XX, con la introducción de los vehículos motorizados es que resultó esencial separar al peatón del tráfico vehicular. Asimismo, el crecimiento económico se reflejaba en el incremento de las actividades comerciales en los centros urbanos que congregaban a una mayor población de clase media en sus calles, siendo necesario facilitar el flujo peatonal que alimentaba el naciente consumismo ${ }^{8}$.

8 La introducción de grandes "tiendas por departamentos" durante el siglo XVIII hizo innecesario el uso de la vereda para publicitar los bienes o como depósito. Las tiendas ocupaban un espacio importante (en algunas ciudades una manzana entera) y se utilizaba la vitrina o el escaparate para exhibir los bienes. En ciudades como Los Ángeles, fueron los dueños de los grandes establecimientos comerciales los que presionaron para que la vereda fuera de exclusivo uso del peatón (Loukaitou-Sideris y Ehrenfeucht, 2012). 
Lima no fue ajena a este impulso y ya hacia las últimas tres décadas del siglo XIX paulatinamente comenzó a adquirir algunas de las características de la ciudad moderna, comenzando con el derrumbe de lo que quedaba de su muralla, con la creación de los grandes parques perimétricos del centro (Exposición, Reserva, Campo de Marte) y otros espacios públicos como la Plaza San Martín, Castilla, Dos de Mayo, paseos y bulevares, entre otros (Günther y Mitrani, 2013). Vega Centeno lo considera como parte de un urbanismo progresista:

La ciudad moderna precisa de vías que permitan unir destinos físicamente distantes a través de desplazamientos que demanden poco tiempo. Por ello, en la ciudad moderna se separan las veredas de las calzadas, dividiendo la antigua calle en espacios destinados a vehículos y franjas asignadas al uso peatonal (2006, p. 17).

La vereda se consolida así como el dominio del peatón y a ser parte del espacio público de la ciudad, es decir gestionado y controlado por el Estado. Esto se refleja con claridad en el Reglamento de Tránsito actual del Perú, desde la misma definición de la "acera" (vereda) como parte de la vía "destinada al uso de peatones" hasta la prohibición de cualquier acción que pueda obstruir el paso de los caminantes por esta vía (sean actividades comerciales, estacionamiento, utilización para flujo vehicular, ampliación del frontis de la vivienda, entre otros).
Desde sus orígenes, las veredas han sido -algo más que el resto del espacio público- un campo de contestación y conflicto debido a que casi siempre es adyacente a la propiedad privada, a lo más próximo e íntimo del poblador de la ciudad. Es lo público más cercano a nuestra residencia y las veredas que nos rodean son las que tradicionalmente marcan y dan forma al barrio. Son vías utilizadas por personas, no por vehículos anónimos, que hasta cierto punto se encuentran aislados en la calzada. Es más probable que se acepte que un auto desconocido transite por las calles del vecindario porque pasa raudo, mientras que el peatón por definición va pausado. Justo por eso, cuando un auto extraño pasa lentamente por el barrio, nos preocupamos porque pensamos que está observándonos (“idebe ser un choro!"). El peatón desconocido, en cambio, perpetuamente es sospechoso porque siempre observa detenidamente, ya que -como dijimos- va a una velocidad propicia para ello.

Con respecto al espacio público, Takano y Tokechi (2007) nos dicen algo muy cierto: no es homogéneo, porque cumple funciones diferenciadas en la ciudad. Así, hay parques, calles y veredas que tienen una clara vocación metropolitana o distrital, mientras que otras tienen una función "barrial" o "vecinal", porque se encuentran aisladas de zonas de alto tránsito y muy cercanas a las residencias, lo cual permite que sean controladas de cerca 
por los vecinos. En estos casos, tiende a existir una mayor apropiación del espacio por los residentes, a privatizarlo y a considerar que el usufructo por "extraños" es inapropiado o inaceptable. Los funcionarios de distritos residenciales NSE A/B entrevistados en el marco de nuestra investigación, por ejemplo, señalaban que uno de los conflictos más comunes de los vecinos con la municipalidad era quién ejercía control sobre el diseño y el uso de los parques, calles y veredas cercanas a áreas netamente residenciales que, a su vez, no eran zonas importantes de tránsito vehicular.

En las páginas que siguen presentamos fotos de algunas de las principales formas de actuación sobre las veredas en los distritos residenciales A/B, en Lima. En cada una de ellas se nota cómo los habitantes visualizan la relación con los otros, en cómo imponen o consensúan usos, en cómo privatizan o alientan la publicidad.

\section{No hay veredas}

En Lima no tienen veredas los barrios muy ricos o los muy pobres. Los primeros no las quieren porque sus residentes tienen acceso a vehículos particulares, no acostumbran a caminar por su urbanización y también porque así evitan la presencia de "otros" que supuestamente no tienen razón para estar en la zona. Básicamente están huyendo del resto de la ciudad y eso lo logran refugiándose en sus viviendas. Los segundos no tienen los ingresos necesarios para habilitar las pistas y veredas, hay otras inversiones que tienen prioridad (agua, electricidad) y los gobiernos locales no priorizan este tipo de gasto. Como bien indica Vega Centeno (2007), el encierro de los barrios de ingresos superiores no es para generar mayor sentido de comunidad, sino como mecanismo para vivir entre parecidos, pero aisladamente. Es más una cuestión de estatus, como nos comentaba uno de los entrevistados en una visita que hicimos en La Encantada de Villa, una comunidad enrejada (gated community):

Nuestra urbanización realmente no constituye un "espacio público", ya que su razón de ser es residencial y por ello se debe a las necesidades de sus vecinos. Es una suerte de espacio "semipúblico" porque sus residentes son las únicas personas -en conjunto con sus invitados- que tienen "razón" o "interés" para estar presentes. Solo debe existir libre tránsito si la zona constituyera algún tipo de patrimonio, centro comercial o lugar turístico de la ciudad, lo cual podría convocar a personas ajenas.

En algunas urbanizaciones de Surco y La Molina se adoptó el modelo de los suburbios norteamericanos en los cuales el acceso a la vivienda es con automóvil. Debido a la baja densidad y reducido flujo de tráfico, en estos suburbios se optó por no contar con vías peatonales. La calzada es considerada en muchas comunidades norteamericanas como lo suficientemente segura como para compartir con los peatones y ciclistas. Esto se nota con claridad en la película Spanglish (2004), cuando 
la madre norteamericana (Téa Leoni) corre por su barrio sin veredas gritando "left, left" a los inmigrantes que transitan por las calles para que mantengan su derecha (le dieran pase a la izquierda), tal cual pide el protocolo de vialidad. Aun así, existen numerosas organizaciones en Estados Unidos que insisten en la imperiosa necesidad de contar con veredas en todas las zonas residenciales 9 .

A diferencia de la mayoría de los suburbios norteamericanos, por las urbanizaciones limeñas transitan muchos caminantes. En primer lugar, así se desplaza todo el personal de apoyo doméstico (trabajadoras del hogar, jardineros, obreros, técnicos) que deben caminar largas distancias antes de encontrarse con una vía con transporte público. En segundo lugar, porque el crecimiento de la ciudad ha hecho que muchas de estas urbanizaciones ya sean parte de una trama urbana densa, con fuerte presencia de centros de servicios y comercio, lo cual genera mayor flujo de transeúntes. Todas las fotos presentadas, por ejemplo, corresponden a urbanizaciones en las inmediaciones de la Universidad de Lima, la avenida Olguín y la vía expresa Javier Prado, a dos o tres cuadras del centro comercial Jockey Plaza y muy cercano al eje comercial de la avenida El Polo, y en la urbanización La Encantada de Villa ${ }^{10}$.

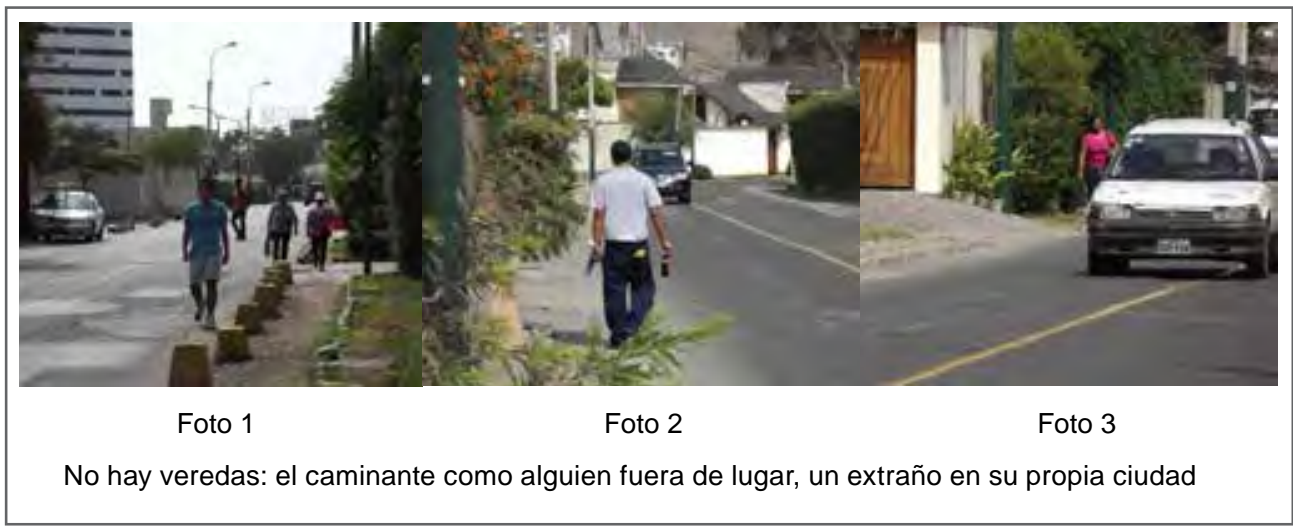

9 Un ejemplo al respecto son las organizaciones pro viandantes en cada estado de Estados Unidos y de Europa, América Latina y Asia, como se puede ver en el siguiente vínculo: http://www.wherethesidewalkstarts.com/p/pedestrian-advocacy-groups.html

10 Las fotos han sido tomadas por el autor del artículo. 
Andar en estas calles es evidentemente peligroso, porque no ofrece garantías mínimas para el peatón. Las bermas -si existen- son estrechas, irregulares y sin sardineles (foto 1). Como no existen áreas de estacionamiento, el pequeño espacio entre la calzada y la vivienda tiende a ser ocupado por autos, lo cual obliga a que los caminantes invadan la calzada (foto 2 ). Los autos deben virar hacia la izquierda al aproximarse a un peatón y al hacerlo invaden el carril contrario (foto 3).

\section{Hay veredas, pero ocupadas}

Antes señalamos que las veredas han sido -desde su invención- un espacio de conflicto porque tiende a ser el equipamiento urbano más próximo a la propiedad privada. Tan ligado está a la vivienda que se espera que cada vecino mantenga limpia y sin obstruir toda la extensión de vereda al frente de su casa. En Lima observamos muchas formas y tipos de obstrucción a las veredas generadas por los vecinos o negocios. Sin embargo, con el crecimiento del parque automotor particular, el principal obstáculo para el libre tránsito peatonal son los vehículos estacionados.

Cuando entrevistamos a los funcionarios encargados de los espacios públicos en siete distritos y a nivel metropolitano, la mayoría coincidió en que el principal problema detectado con respecto al espacio público es el incremento del parque automotor y el efecto que tiene sobre aquel, especialmente las pistas y veredas. La presión por estacionamientos afecta estas áreas públicas, no solo por los motoristas que son extraños al barrio, sino principalmente por los mismos residentes que sienten, además, que tienen derecho sobre la vereda y la pista adyacente. El boom de la construcción en la ciudad también plantea otra forma común de obstrucción de la vereda.

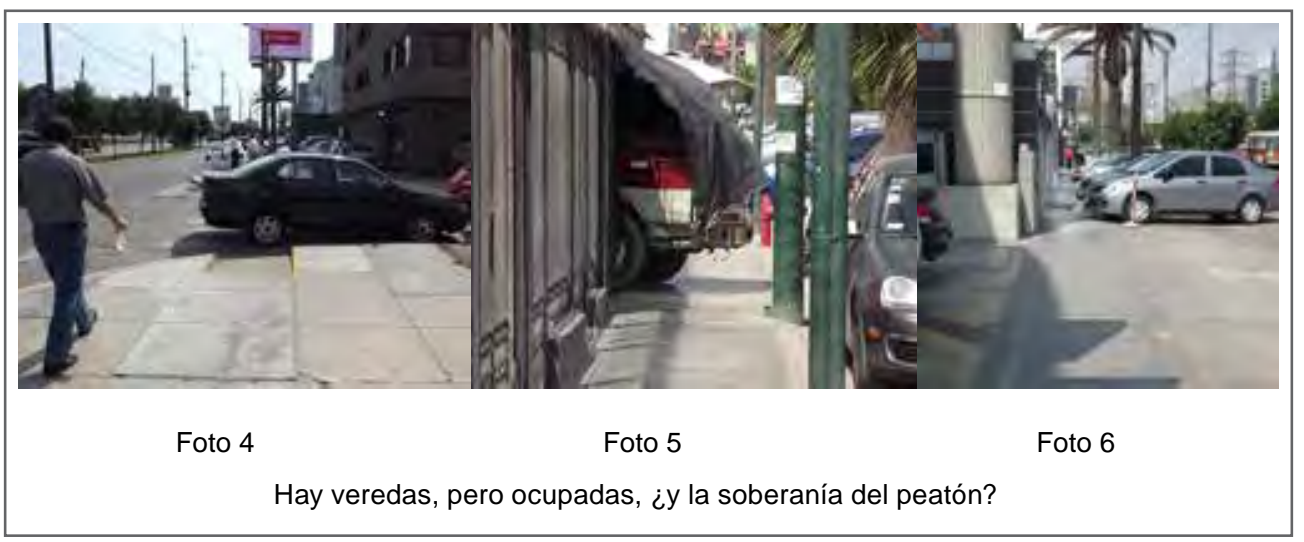


En nuestros recorridos encontramos múltiples casos de veredas obstruidas de una forma $u$ otra. En la foto 4 vemos un auto estacionado obstruyendo la rampa que permite la circulación de sillas de ruedas y diversos tipos de coches, triciclos $u$ otras modalidades de desplazamientos para niños y niñas pequeños. $Y$ no había estacionado por un período breve -como parando para comprar en la bodega- ya que en la hora que estuvimos paseando por la zona se mantuvo ahí. Lo visto en la foto 5 me sorprendió, a pesar de ser un experimentado andante en una ciudad como la nuestra. Es un pequeño camión que no llega a entrar plenamente en el garaje de la vivienda y, por ende, ocupa buena parte de la vereda. Lo que más llama la atención, y lo que muestra la "naturalidad" con la que invade la acera, es que el vehículo está tapado con un material oscuro para que no le caiga el sol. Finalmente, tenemos en la foto 6 lo más común en nuestra ciudad: el estacionamiento frente a locales comerciales $\mathrm{u}$ oficinas que casi siempre terminan invadiendo toda la vereda o parte de ella.

\section{Hay veredas, pero no para ti}

Los antecedentes inmediatos a la práctica de cerrar calles públicas en Lima se remontan a los años de violencia política en el Perú y el temor a los "coche-bombas". Diversos es- tudios tienden a hacer hincapié, sin embargo, que el boom de las calles enrejadas realmente comienza hacia finales de los años noventa y el inicio del nuevo milenio (Plöger, 2007; Ledgard y Solano, 2011), en respuesta a una creciente preocupación por la seguridad ciudadana. Plöger, no obstante, considera que la inseguridad es solo uno de los tres factores que explican la "descomposición de lo social" que se encuentra detrás del enrejado de Lima. Los otros factores son la persistencia de la desigualdad -a pesar del crecimiento económico-y la ineficiencia del Estado.

La extensión y visibilidad del fenómeno llevó incluso a que la Defensoría del Pueblo se pronunciara. Sus conclusiones y recomendaciones claramente señalan que

las vías públicas constituyen el medio que garantiza el ejercicio de la libertad de tránsito, circulación o locomoción. El uso común de las vías públicas se rige por los principios de igualdad, libertad y gratuidad, ya que constituyen bienes de dominio y uso público, es decir, el único titular sobre ellas es el Estado y, por tanto, es el único que puede establecer limitaciones o restricciones sobre ellas (2004, p. 41).

Hace hincapié, además, en que el libre tránsito es un derecho constitucional, mientras que la seguridad ciudadana es más bien un servicio público, razón por la cual no puede ser pretexto para impedir el ejercicio 
del libre tránsito ${ }^{11}$. La Municipalidad Metropolitana promulgó las ordenanzas 690 (2004) y 744 (2005), que claramente establecen los procedimientos que deben seguir las municipalidades distritales para la autorización de los elementos de seguridad y cómo estos deben ser operados ${ }^{12}$.

No existen datos precisos acerca del número de calles afectadas. Los estudios existentes son parciales y basados en muestras, inventarios municipales o reportajes periodísticos. En 2004, el geógrafo Jörg Plöger (2007) contabilizó 3000 barreras y aproximadamente 300 enclaves residenciales. Basó su cálculo en información periodística, visitas a todos los distritos y datos proporcionados por las municipalidades. La Asociación Peruana de Consumidores y Usuarios (Aspec) realizó un estudio parcial de las calles enrejadas en Lima en el año 2010, visitaron 18 distritos y contabilizaron 1263 calles enrejadas. El dato sorprendente y preocupante fue que solo $9 \%$ de las rejas tenían autorización y un porcentaje aún menor cumplía con todos los requisitos legales (7\%). En la encuesta hecha en el marco de esta investigación, el 16,2\% de los informantes señalaron que vivían en una zona con las vías restringidas por tranqueras $(9,0 \%)$ o por ser una comunidad enrejada $(7,2 \%)$.

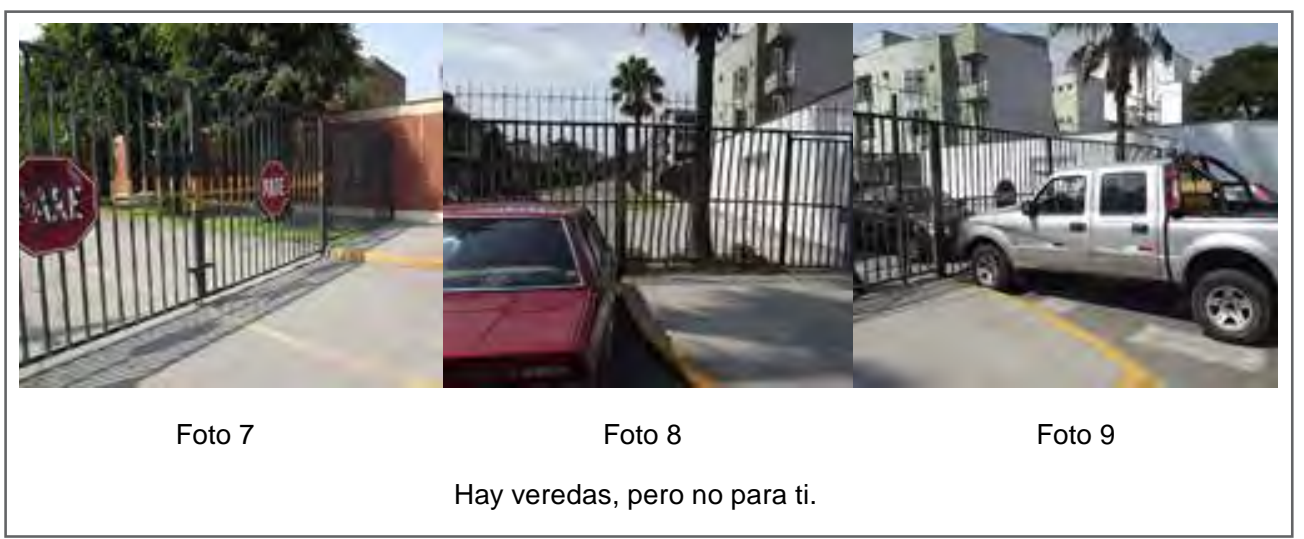

11 Al momento de elaborar el Informe Defensorial, ya existían por lo menos tres sentencias del Tribunal Constitucional favorables a demandantes que exigían el retiro de rejas y tranqueras en las vías públicas (véase Defensoría del Pueblo, 2004, pp. 36-39).

12 De acuerdo a la Ordenanza 690, existen tres criterios para autorizar restricciones del libre tránsito en una calle: (a) excepcionalidad, debe demostrarse un riesgo fehaciente que pone en peligro la seguridad; (b) temporalidad, considerando que los impedimentos se retirarán paulatinamente al disminuir el riesgo; (c) accesoriedad, considerando que estas medidas no reemplazan o complementan las labores de la Policía Nacional y los gobiernos locales en términos de seguridad ciudadana. 
Resulta difícil caminar en muchas urbanizaciones de Lima, no por falta de habilitación urbana, sino por pura prepotencia al haberse apropiado ilícitamente el espacio que nos pertenece a todos. En las fotos vemos claramente cómo las rejas cercenan la ciudad y afectan el derecho al libre tránsito. Lo peor de todo es que -según el informe de la Defensoría mencionado- estas rejas no disminuyen la delincuencia, pero sí los derechos. Quizás no haya factor que me genere mayor reprobación como caminante que estos obstáculos. Y según la última encuesta de "Lima cómo vamos" (2014), un poco más de la mitad de los limeños y limeñas $(52,6 \%)$ opinan de igual manera: que tenemos el derecho de transitar por calles y parques sin restricciones.

Debemos insistir que diversos estudios nacionales e internacionales señalan, sin embargo, que las calles enrejadas no solo expresan una preocupación acerca de la seguridad, sino que constituyen una forma encubierta de segregación social. Según Giglia (2008), en su estudio realizado en la ciudad de México, es una estrategia socioespacial que también expresa la búsqueda de formas de diferenciación respecto a los de "afuera" y el logro de una mayor homogeneidad sociocultural dentro de la urbanización o vecindario. En el caso de Lima, varios autores enfatizan el aspecto discriminatorio que -a pesar de construirse sobre un real aumento en la criminalidad-se evidencia en el hecho de que los "peligrosos" son invariablemente definidos como integrantes de niveles socioeconómicos inferiores o son juzgados por su apariencia (Plöger, 2007; Vega Centeno, 2006, 2007; Ledgard y Solano, 2011; Ludeña, 2011).

\section{El peatón al cruzar la calzada}

El caminante limeño primero debe afrontar, como hemos visto, diversos problemas al usar las veredas, a pesar de ser aquella parte de la vía que le corresponde, pero hemos visto que a veces no existen, están obstruidas o cerradas al transeúnte. Mayor problema debe enfrentar, sin embargo, al momento de sentar pie en la calzada, definida en nuestro Reglamento de Tránsito como "parte de la vía destinada a la circulación de vehículos y eventualmente [cursivas mías] al cruce de peatones y animales". Es evidente que el cruce de la calzada por parte del peatón es mucho más que una eventualidad, sino un hecho tan común y ordinario como caminar en las veredas. Sin embargo, la "eventualidad" significa que el peatón está dejando su vía -relativamente segura- para aventurarse en los dominios de los autos, buses, camiones y motocicletas.

Si muchos de los derechos del peatón no son respetados en la vereda, lo que ocurre en la calzada es atroz. Urbanistas y sociólogos urbanos siempre afirman que el estudio de los tipos y formas de los espacios públicos resulta esencial para entender las dinámicas de la ciudad e, inclusive, "tiene relación 
directa con las prácticas socioespaciales, el respeto a las normas, el sentido y el concepto del 'otro'"' (Formiga, 2007, p. 210). Según Jordi Borja "la calidad, la multiplicación y la accesibilidad de los espacios públicos definen en gran medida la ciudadanía" (2001, p. 210).

¿Qué podríamos decir, entonces, de nuestra ciudadanía a la luz del tratamiento que reciben los peatones? En un informe de la Organización Mundial de Salud, del 2009, el Perú figuraba como el país con el mayor porcentaje de peatones víctimas fatales de accidentes viales al ser comparado con 178 naciones (Vega Centeno, 2011). Con los peatones representando el $78 \%$ de las muertes por accidentes de tránsito, superaba a Chile (40\%) y simplemente se encontraba a leguas de Francia (12 \%) y Bélgica (9,7\%). En una encuesta reciente (marzo de 2015) de Ipsos-El Comercio, el $93 \%$ de los limeños dijeron que en los últimos treinta días habían observado a peatones que no respetaron el semáforo o cruce peatonal y el 90 \% había observado a conductores pasarse la luz roja. Inclusive, el $80 \%$ había sido testigo de un choque y un ;66 \%! dijo haber observado un atropello ${ }^{13}$.

Es evidente que, en una democracia, todos somos iguales ante la ley y que esta igualdad solo toma cuerpo en sociedades en las cuales se respetan las normas. Al momento de interactuar el peatón con los conductores se está poniendo a prueba el sistema de derechos y responsabilidades que enmarcan la convivencia democrática. Las leyes y sus reglamentos privilegian al peatón porque es el transeúnte más vulnerable en el espacio público. Lo protege de los posibles abusos y prepotencia de los conductores que por masa y velocidad gozan de mayor fuerza. Las normas buscan imponerse sobre la fuerza bruta y así garantizar la seguridad del caminante. Si este sistema de reglas y respeto no funciona en la práctica, entonces nos está diciendo algo muy serio sobre el estado de la institucionalidad democrática y la ciudadanía en nuestra ciudad y nuestro país. En vez de convivencia, pasamos a la "ley de la selva", donde el "más fuerte" impone sus condiciones.

Diversas organizaciones nacionales insisten en que la falta de respeto a los peatones y los accidentes que sufren es producto de una serie compleja de hechos, en los cuales resaltan la falta de una cultura vial, la ausencia de infraestructura y señalización adecuada, el mal diseño de vías y cruces $\mathrm{y}$, también, la falta de cumplimiento de las normas. No pretendo entrar en un debate sobre la relativa importancia de cada uno de estos factores porque no es el lugar o el momento, más bien me gustaría aterrizar en nuestras dificultades por cumplir las normas. $Y$ para ello quiero analizar las fotos que se presentan a continuación.

13 Diario El Comercio. Lima, 17 de marzo de 2015, página A8, acceso digital. 


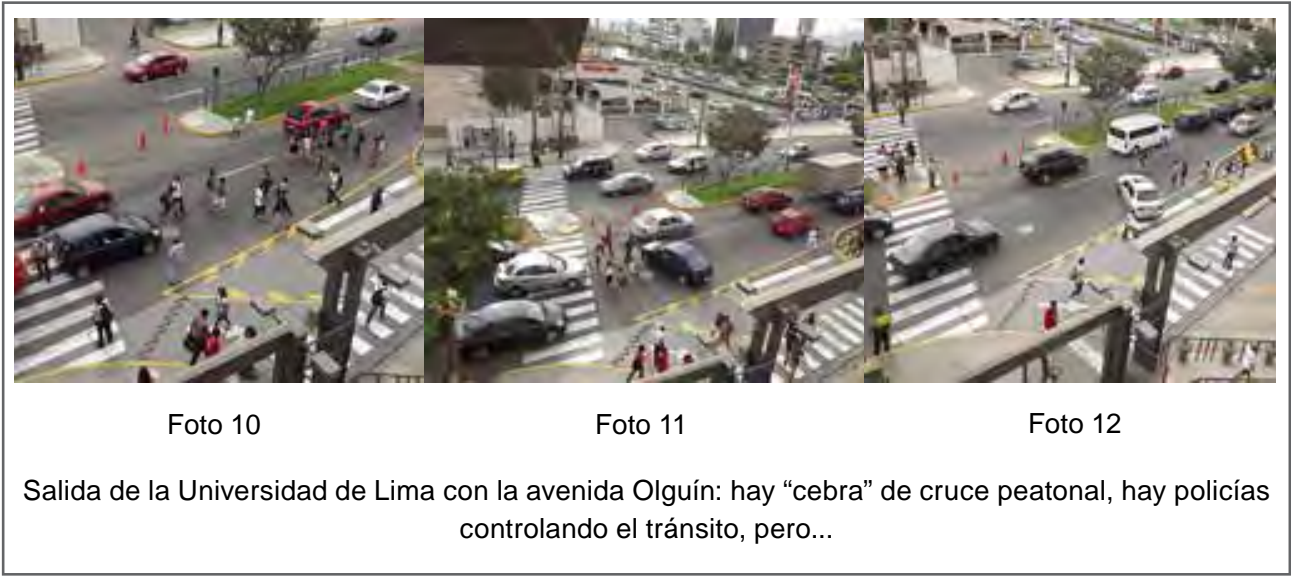

Para esta serie de fotografías quisimos congregar todas las condiciones ideales para que el peatón y el motorista pudieran interactuar según lo indicado en el reglamento de tránsito. En otras palabras, quisimos controlar por las otras variables que los expertos dicen que afectan negativamente a la conducta del peatón y el conductor. Como se puede observar en las fotos, los cruces de los peatones están claramente marcados en la vereda -a la salida del estacionamiento de la universidad- y en la avenida Olguín. Son veredas amplias que no se encuentran obstaculizadas. Además, ambos lados de la avenida cuentan con policías que -en intervalos- detienen el tráfico vehicular para darles paso a los peatones.

Lo que observamos es que un buen número de los peatones y conductores no hacen caso. Los peatones cruzan por todas partes y con todo tipo de dirección, a pesar de que el reglamento señala que el peatón siempre debe cruzar: la calzada por la zona señalizada o demarcada especialmente para su paso. En las intersecciones no señalizadas, el cruce debe realizarse en forma perpendicular a la vía que cruza, desde una esquina hacia otra, y de ser el caso, atendiendo las indicaciones de los Efectivos de la Policía Nacional del Perú. Debe evitar cruzar intempestivamente o temerariamente la calzada (artículo 68).

Los motoristas, a su vez, se paran sobre el cruce peatonal que está claramente pintado. $\mathrm{Y}$ todo a la vista y paciencia de los efectivos policiales.

Nuestra actuación en el espacio público es un reflejo -como dijimosde nuestras actitudes con respecto a la ley y los derechos. Como he analizado en un trabajo anterior, al examinar el capital social en Lima, nuestra tendencia es a personalizar o relativizar la norma (Díaz-Albertini, 2010). El acatamiento depende de: (a) si me conviene; (b) si me obligan; $y$, finalmente, (c) si quiero hacerlo porque lo considero apropiado socialmente. 
Solo en el último caso es que podemos hablar de la "legitimidad de la norma" y en nuestra sociedad tiende a ocurrir cuando sentimos que los demás son nuestros iguales $\mathrm{y}$, por ende, queremos que todos sean tratados de la misma manera. Esta diferenciación explica por qué los conductores en un club privado o en un condominio sí respetan las normas de tránsito (límite de velocidad, no tocar claxon, respetar el cruce de peatones, entre otros), pero al salir al espacio público no acatan reglas y vulneran derechos.

En las fotos mostradas, los conductores y peatones hacen caso omiso de las normas que permiten una segura convivencia entre los ciudadanos. Para muchos peatones, hemos observado que les resulta más cómodo descender del puente peatonal e inmediatamente cruzar, si las condiciones lo permiten. El trasladarse unos treinta metros hasta el cruce peatonal es una pérdida de tiempo. Los conductores, a su vez, consideran que la calzada es su vía y que toda presencia peatonal es una suerte de "invasión" que con las justas debe ser tolerada. Por suerte hay policías en cada uno de los sentidos de la avenida. Sin embargo, una cuadra más adelante, en la intersección con la avenida Javier Prado, hay cruce peatonal, pero no hay policía... pero debido al intenso tráfico de esa avenida los vehículos que vienen por Olguín avanzan lentamente y ello permite que, de vez en cuando, los peatones puedan cruzar esta vía culebreando entre los autos.

\section{La berma central y el lento camino hacia el civismo}

En mis andanzas por el distrito de San Isidro, comencé a observar que -con cierta regularidad- en los alrededores del club El Golf encontraba en las veredas y en las bermas centrales -aquellas con jardines, como en la avenida Coronel Portillo- botellas de plástico arrojadas.

Al principio no me llamaba la atención, porque como buen caminante limeño sabía bien que muchos transeúntes (en vehículos o a pie) no tenían mayor respeto por las reglas de convivencia (civismo) y tampoco eran corteses, atentos o con buenos modales (urbanidad). Por el contrario, con frecuencia se comportaban como si la ciudad fuera un enorme basurero.

Con el tiempo, sin embargo, percibí que las botellas no estaban vacías, sino que muchas contenían un líquido amarillento. Me había topado con un fenómeno que decidí llamar "orín embotellado". Tan curiosa costumbre me llevó a fotografiarla cuando salía a caminar o correr y me límite a hacerlo en un área determinada de tres cuadras de la avenida Coronel Portillo, aquella que se encuentra entre las avenidas Miró Quesada y Pezet. Y aunque al principio me parecía una muestra más de las barbaridades que cometemos en los espacios públicos, con el tiempo fui apreciándola de una manera más optimista. En la página 190 se incluye una selección de las fotos. 
Casi todas las botellas se encontraban en la berma central de la avenida en cuestión, y solo de vez en cuando estaban depositadas en la vereda, o por lo menos en el área que podríamos denominar como cuneta (aunque Lima no las tenga). Es decir, no eran dejadas en el medio de la calzada propiamente dicha, sino puestas a un costado, donde sería recolectada por las barrenderas de la municipalidad. Inclusive, comencé a apreciar la consideración de los anónimos embotelladores, porque si las dejaban en el medio de la pista, con toda seguridad serían aplastadas por los autos y su contenido saldría con gran presión, salpicando a los caminantes, trotadores, corredores y ciclistas que abundan en la zona.

También decidí 'googlear', en castellano y en inglés (usando como palabras búsqueda "orinando en botella" y peeing in a bottle, respectivamente) para ver cuán extendida era esta costumbre. En términos generales, encontré en ambos idiomas que era una práctica recomendada para los que viajan largas distancias en auto o en bus. No recomendaban, sin embargo, que fuera arrojada a la vía. También descubrí que en algunas zonas de Estados Unidos estaba au- mentando la presencia de estas botellas en carreteras solitarias y que los camioneros tendían a ser los culpados -tanto es así que las botellas son denominadas trucker bombs ("bombas de camioneros")- aunque también algunos reportajes alertaban que se estaba incrementando esta práctica entre otros tipos de motoristas. Inclusive varios estados han iniciado campañas en su contra, al promulgar normas prohibiendo este hábito y multando a quienes lo realizan ${ }^{14}$.

La pesquisa, aunque no fuera exhaustiva, claramente indicaba que los posibles embotelladores debían ser aquellos conductores que permanecían largas horas en sus vehículos y no tenían acceso a los servicios higiénicos. Ello limita nuestros sospechosos a los choferes de servicio público y a los taxistas. Los primeros, sin embargo, casi siempre tienen pasajeros, lo cual dificulta la tarea, mientras que los taxistas se pasan largos períodos sin pasajeros. De nuevo, al 'googlear', noté que en Lima era bastante común asociar el acto de orinar en público con los choferes de taxi. En nuestra ciudad, un taxista tiende a manejar en turnos de doce a catorce horas seguidas, existen pocos baños públicos, o están ubicados en

14 Según informó el New York Daily News en el 2012, el estado de North Dakota sufre este problema debido al "boom del petróleo", que surge al descubrirse nuevos yacimientos en el 2006, lo cual ha atraído gran cantidad de empresas de transportes y aumentado el flujo de carga, pero hacia zonas con poca infraestructura en las carreteras, especialmente servicios higiénicos en los lugares de descanso (Rest stops). Recuperado de http://www.nydailynews. com/news/national/north-dakota-confronts-nasty-trucker-bomb-problem-article-1.1050862 


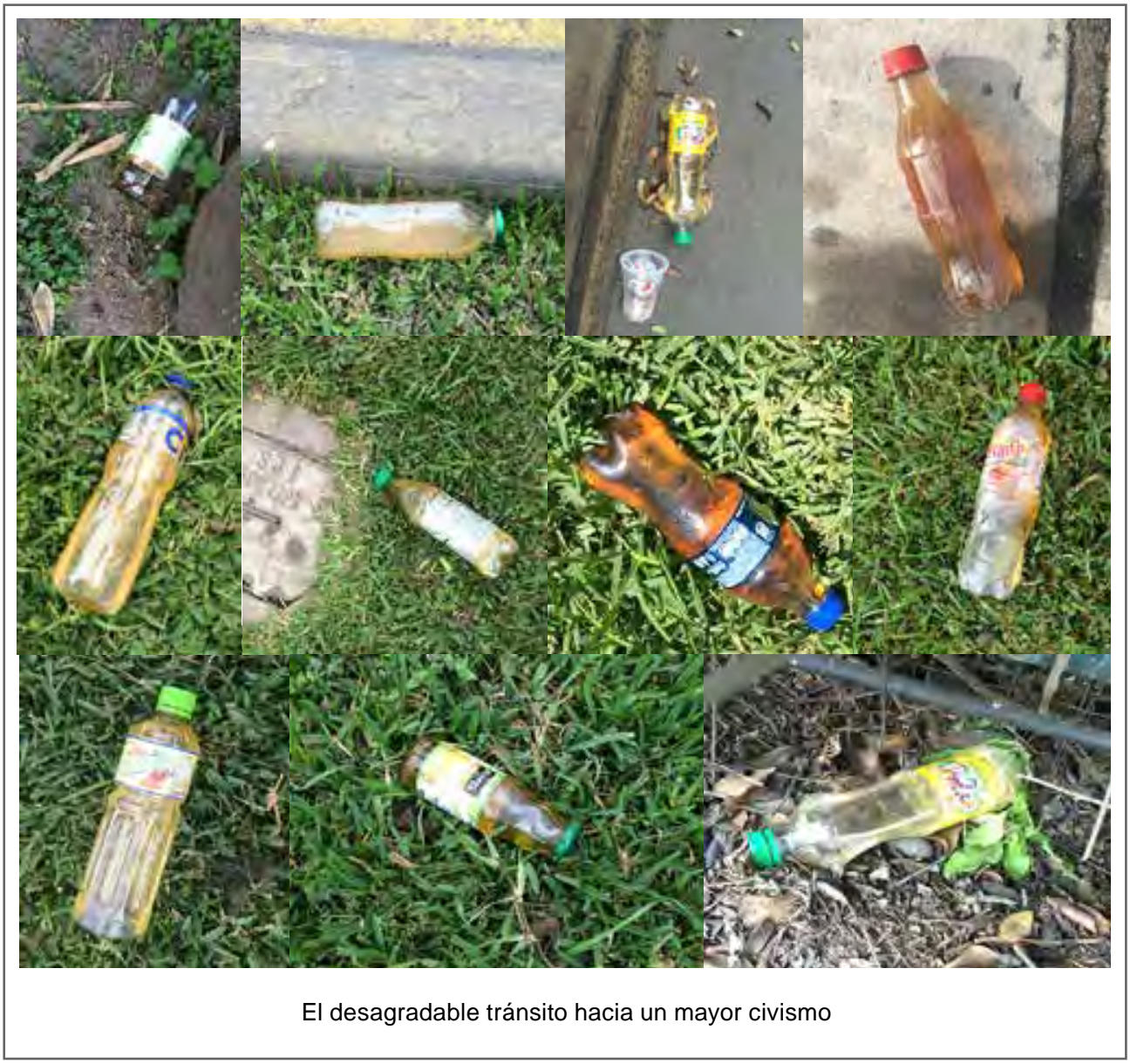

sitios en los cuales resulta difícil estacionar. Los establecimientos privados -incluidos los grifos o estaciones de gasolina- también son reacios a prestar sus baños. Por ello, los taxistas se habían hecho conocidos por orinar en las calles y parques.

¿Pero por qué el cambio de práctica de orinar directamente en la calle a hacerlo dentro de una botella? De nuevo, resulta difícil encontrar una respuesta inequívoca, pero sí es posible espe- cular. En primer lugar, el cambio de conducta tiene mucho que ver con la importancia relativa que las respectivas municipalidades están prestando (o pueden prestar) a los espacios públicos, a la contaminación y al medio ambiente. Las diferencias en la importancia otorgada se notan, por ejemplo, en los programas que penan el ensuciamiento de la vía pública con desechos de mascotas. Todos los distritos de Lima tienen ordenanzas que penan 
esta práctica, pero solo veintiocho la han reglamentado y únicamente un puñado tiene los programas, realizan las campañas e invierten en la infraestructura que facilita el cumplimiento de dicha norma por parte de la ciudadanía ${ }^{15}$. Asimismo, también este grupo reducido de municipalidades tiene la posibilidad de hacerles seguimiento y sancionar. En los distritos que cuentan con norma, reglamento, difusión, sensibilización y capacidad de sanción se está logrando un cambio positivo en la conducta de los vecinos, aunque ello a veces signifique -desa- fortunadamente- mayores restricciones en los espacios públicos (véase el recuadro 1$)$.

La hipótesis que manejamos es que en distritos como San Isidro los taxistas han tenido que adoptar un comportamiento que -lejos de ser cívico- comienza a aproximarse a un mayor respeto a las normas, sean municipales o de convivencia. Resulta cada vez más difícil que la municipalidad y los vecinos toleren la micción pública. Asimismo, son distritos que han realizado una fuerte inversión en seguridad ciudadana, lo cual implica que

\section{Recuadro 1}

En los grupos focales con mujeres del NSE A, se verbalizaba la contradicción entre tener parques y calles abiertos, al mismo tiempo que se exige mayor control sobre determinadas poblaciones.

Moderadora: ¿Qué opinan de todas estas limitaciones (al espacio público)?

- Se llega a eso, porque la gente no cuida. Tú ves cómo la gente tira la cáscara de plátano por la ventana.

- O están orinando frente al parque de tu casa...

- En San Isidro varios taxistas usaban el parque para descansar un rato y de paso botaban su 'pichi'. Por eso, San Isidro cerró esa especie de estacionamiento para que nadie se estacione allí.

- Eso es por la misma queja de los vecinos, el municipio les hace caso.

- Me imagino que será para que no vaya gente desconocida a hacer cosas, no lo sé. Como también hay niños. Hay padres que sacan a sus hijos 7 u 8 de la noche.

15 Véanse, al respecto, las siguientes noticias en: http://elcomercio.pe/lima/ciudad/casinunca-cobran-multas-excretas-perros-via-publica-noticia-1710651; y en: http://www. andina.com.pe/agencia/noticia-digesa-75-ciento-municipios-incumple-ordenanzasobre-tenencia-canes-330996.aspx. 
buena parte del territorio está vigilado, sea en forma directa o mediante cámaras ${ }^{16}$. Resulta curioso, por ejemplo, que en un reportaje del noticiero del Canal 5 (4 de enero de 2015) que justo denunciaba la orinada pública en el centro de la ciudad, una de las personas entrevistadas relate que fue "detenido en la comisaría" por orinar en San Isidro ${ }^{17}$.

No quiero dejar la impresión de que los residentes de mayores ingresos son "más cívicos". En este artículo hemos sido claros en demostrar cómo estos mismos vecinos discriminan a otros limeños y cómo tratan las veredas, las calles y los parques como si fueran su propiedad privada. Lo que quiero resaltar es la importancia de la acción conjunta Estadosociedad civil, que es facilitada por un incremento en lo que se denomina "capital social gubernamental" (Collier, 1998). Es decir, es un capital que mide la capacidad del Estado de garantizar la seguridad jurídica (por ejemplo de la propiedad y los contratos), el imperio de la ley y los marcos para la resolución de conflictos. Este es un cambio esencial en una sociedad ya caracterizada por un Estado tolerante a la transgresión -sea informal o delictiva- y que se ha acostumbrado a aceptar la anomia bajo el pretexto de que hay otros asuntos más importantes a los cuales debe prestar atención, como el crecimiento económico o la inseguridad ciudadana (Durand, 2013).

Lo ideal es que todos los habitantes utilicen los servicios higiénicos o, en todo caso, que el orín en botella sea depositado en basureros. Pero para dar este paso resultaría necesario el trabajo conjunto de las municipalidades, con los choferes y la sociedad civil. Implica reconocer el hecho de que nuestra ciudad tiene un $130 \%$ de superávit de taxis, que por ello la competencia es feroz y que cada instante en la caza de pasajeros es considerado crucial $^{18}$. Como bien lo acuñó Bielich (2009), es una "guerra del centavo". Asimismo, existen solo 142 baños públicos, que han sido instalados por la municipalidad, en nuestra ciudad de 9 millones de habitantes, y algunos distritos residenciales -como San Borja,

16 Solo basta comparar el número de habitantes por sereno o por policía en los distritos de Lima para darnos cuenta de la capacidad de control. En 2009, San Isidro tenía 133 habitantes por sereno y 211 por policía, mientras que San Juan de Lurigancho tenía 2056 por sereno y 1298 por policía (Costa y Romero, 2010a).

17 http://panamericana.pe/eldominical/locales/173223-lima-letrina-malos-habitos-convierten-capital-bano-publico. La entrevista al "detenido" es en 5:52.

18 http://elcomercio.pe/lima/transporte/lima-sobran-taxis-hay-130-mas-lo-que-se-necesitaria-noticia-1797328. 
Surco, La Molina y Pueblo Libre- no tienen ninguno ${ }^{19}$.

\section{Conclusión}

Hemos querido presentar algunos aspectos de una ciudad agresiva, hostil y peligrosa para sus caminantes. Consideramos que una de las principales causas detrás del abuso al peatón es la creciente privatización -definida como apropiación por particularesdel espacio público. En el proceso de negar un adecuado acceso y uso al peatón del espacio público, estamos rebajando su estatus ciudadano porque vulneramos sus derechos, especialmente al libre tránsito. A pesar de que se vulneran estos derechos, bajo el pretexto o la justificación de protegerse de la inseguridad ciudadana, resulta evidente que también hay un deseo profundo de distanciarse y distinguirse del "otro". Se va produciendo así una ciudad archipiélago (Vega Centeno, 2007) que se resiste a crear, fortalecer y defender los espacios de encuentro y afirmación de vecindad y ciudadanía. Finalmente, consideramos que la inacción y falta de atención de los gobiernos facilita esta privatización y apropiación.
No hemos tenido tiempo de mostrar la otra Lima, la urbe en ciernes, aquella que anunciamos al principio de este artículo. Estamos pensando en la ciudad que comienza a reconocer los derechos de los caminantes y ciclistas, en la cual diversos usuarios comparten espacios -como en el malecón de Miraflores- y se vive la multifuncionalidad. Lugares que han sido creados gracias a la sinergia gobierno-ciudadanos y cuya gestión es difícil -por la diversidad de intereses- pero dialogada. Esto lo haremos en otra ocasión...

\section{Referencias}

Appleyard, D. (1981). Livablestreets. Berkeley: University of California Press.

Appleyard, B. (2005). Livable streets for schoolchildren. NCBW Forum. Article 3-7-05. Recuperado de http:// www.activeliving.org/files/Livable_ streets_for_schoolchildren.pdf

Aspec-Asociación Peruana de Con-sumidores y Usuarios. (2010). Lima entre rejas. Informe especial, 1-9. Lima.

Bielich, C. (2009). La guerra del centavo: una mirada actual al transporte público en Lima metropolitana. Lima: Instituto de Estudios Peruanos.

19 Registro Nacional de Municipalidades 2014 (INEI), en resultados por distritos, examinar servicios municipales y el cuadro \#40 (http://www.inei.gob.pe/estadisticas/encuestas/). 
Borja, J. (2001). Ciudadanía y espacio público. En D. Jiménez (Comp.), Laberintos urbanos en América Latina. Quito: Abya-Yala.

Collier, P. (noviembre de 1998). Social capital and poverty. Social Capital Initiative Working Paper, 4. World Bank.

Costa, G. y Romero, C. (2010a). Los serenazgos en Lima: ¿les ganan las calles a la policía? Lima: Ciudad Nuestra.

Costa, G. y Romero, C. (2010b). Inseguridad ciudadanía en Lima. ¿Qué hacer? Lima: Ciudad Nuestra.

Defensoría del Pueblo-Perú. (2004). Libertad de tránsito y seguridad ciudadana: los enrejados en las vías públicas de Lima metropolitana. Informe Defensorial, 81. Recuperado de http://www.defensoria.gob.pe/ informes-publicaciones.php

Díaz-Albertini, J. (2010). Redes cercanas. El capital social en Lima. Lima: Universidad de Lima, Fondo Editorial.

Díaz-Albertini, J. (2012). El espacio secuestrado: feudos, comarcas y ferias en la Lima de principios del siglo XXI. En J. Mejía (Ed.), América Latina en debate: sociedad, conocimiento e intelectualidad. Lima: Universidad Ricardo Palma.

Durand, F. (2013). Socioeconomías informales y delictivas. En W. Jungbluth (comp.), Perú hoy, el Perú subterráneo. Lima: Centro de Estudios y Promoción del Desarrollo (Desco).

Formiga, N. (2007). El derecho a la ciudad y la cuestión del espacio público: Experiencias en la ciudad de Bahía Blanca. Journal of Latin American Geography, 6(1), 173-196.

Francis, M. (1991). The making of democratic streets. En A. Vernez (Ed.), Public streets for public use. Nueva York: Columbia University Press.

Giglia, A. (2008). Gated communities in Mexico City. Home Cultures, 1(5), 65-84.

Gonzales de Olarte, E., Del Solar, V., y Del Pozo, J. M. (2011). Lima metropolitana después de las reformas neoliberales: transformaciones económicas y urbanas. En C. de Mattos, W. Ludeña y L. Fuentes (Eds.), LimaSantiago. Reestructuración y cambio metropolitano. Lima: Pontificia Universidad Católica del Perú.

Günther, J., y Mitiani, H. (2013). Memorias de Lima. Tomo IV. Lima: Empresa Editorial El Comercio.

Ledgard, R., y Solano, A. (2011). Lima: transformaciones en la estructura e imagen de la metrópoli. Situación actual y perspectivas. En C. de Mattos, W. Ludeña y L. Fuentes (Eds.), LimaSantiago. Reestructuración y cambio metropolitano (21-40). Lima: Pontificia Universidad Católica del Perú.

Lima cómo vamos (2014). Encuesta. Recuperado de http://www.limacomovamos.org/noticias/descargala-quinta-encuesta-lima-como-vamos-2014/

Logan, J. R., y Molotch, H. (2007). Urban fortunes: the political economy of place. Los Angeles: University of California Press. 
Ludeña, W. (2011). Lima: transformaciones urbanas y reestucturación morfológica. Urbanismo, vivienda y centro histórico. Período 19902007. En C. de Mattos, W. Ludeña y L. Fuentes (Eds.), Lima-Santiago. Reestructuración y cambio metropolitano. Lima: Pontificia Universidad Católica del Perú.

Loukaitou-Siderios, A., y Ehrenfeucht, R. (2012). Sidewalks: conflict and negotiation over public space. Cambridge, MA: MIT Press.

MTC-Ministerio de Transportes y Comunicaciones. (2009). La vulnerabilidad de los peatones en la vialidad del área metropolitana de Lima y Callao. Recuperado de: https://www.mtc.gob.pe/portal/Vulnerabilidad $\% 20 \mathrm{de} \% 20$ Peatones\%20-\%20Informe\%20Final. pdf

Plöger, J. (2007). The emergence of a "city of cages" in Lima: neighbourhood appropriation in the context of rising insecurities. Cybergeo: European journal of geography (377). Recuperado de: http://cybergeo.revues.org/6785\#quotation

Protzel, J. (2013). Espacio-tiempo y movilidad: narrativas del viaje y de la lejanía. Lima: Universidad de Lima, Fondo Editorial.

Pucher, J. y Dijkstra, L. (setiembre de 2003). Promoting safe walking and cycling to improve public health: lessons from the Netherlands and
Germany. American Journal of Public Health, 93(9), 1509-1516.

Smalldone, D., Harris, C. y Sanyal, N. (2008). The role of time in developing place meanings. Journal of Leisure Research, 40(4), 479-504.

Takano, G. y Tokechi, J. (2007). Espacio público en la ciudad popular: reflexiones y experiencias desde el Sur. Lima: Centro de Estudios y Promoción del Desarrollo (Desco), Serie Estudios Urbanos N. 3.

Vega Centeno, P. (diciembre de 2006). El espacio público: la movilidad y la revaloración de la ciudad. Cuadernos Arquitectura y Ciudad, 3. Lima: Pontificia Universidad Católica del Perú, Departamento de Arquitectura.

Vega Centeno, P. (2007). Estratificación social: los dilemas del espacio público en la Lima del siglo XXI. En O. Plaza (Coord.), Clases sociales en el Perú: visiones y trayectorias (321343). Lima: Pontificia Universidad Católica del Perú.

Vega Centeno, P., Dextre J. C., y Alegre, M. (2011). Inequidad y fragmentación: movilidad y sistemas de transporte en Lima metropolitana. En C. de Mattos, W. Ludeña y L. Fuentes (Eds.), LimaSantiago. Reestructuración y cambio metropolitano (289-328). Lima: Pontificia Universidad Católica del Perú.

Xu, M., y Yang, Z. (2008). Theoretical debate on gated communities: genesis, controversies, and the way forward. Urban Design International, 13, 213-226. 